\title{
On the convergence of fixed points for Lipschitz type mappings in hyperbolic spaces
}

\author{
Shin Min Kang ${ }^{1 *}$, Samir Dashputre², Bhuwan Lal Malagar ${ }^{2}$ and Arif Rafiq ${ }^{3}$
}

\section{${ }^{*}$ Correspondence:}

smkang@gnu.ac.kr

1 Department of Mathematics and

RINS, Gyeongsang National

University, Jinju, 660-701, Korea

Full list of author information is

available at the end of the article

\section{空 Springer}

\begin{abstract}
In this paper, we prove strong and $\Delta$-convergence theorems for a class of mappings which is essentially wider than that of asymptotically nonexpansive mappings on hyperbolic space through the S-iteration process introduced by Agarwal et al. (J. Nonlinear Convex Anal. 8:61-79, 2007) which is faster and independent of the Mann (Proc. Am. Math. Soc. 4:506-510, 1953) and Ishikawa (Proc. Am. Math. Soc. 44:147-150, 1974) iteration processes. Our results generalize, extend, and unify the corresponding results of Abbas et al. (Math. Comput. Model. 55:1418-1427, 2012), Agarwal et al. (J. Nonlinear Convex Anal. 8:61-79, 2007), Dhompongsa and Panyanak (Comput. Math Appl. 56:2572-2579, 2008), and Khan and Abbas (Comput. Math. Appl. 61:109-116, 2011).

MSC: $47 \mathrm{H} 10$

Keywords: S-iteration process; uniformly convex hyperbolic space; nearly asymptotically nonexpansive mapping
\end{abstract}

\section{Introduction}

The class of asymptotically nonexpansive mappings, introduced by Goebel and Kirk [1] in 1972, is an important generalization of the class of nonexpansive mapping and they proved that if $C$ is a nonempty closed and bounded subset of a uniformly convex Banach space, then every asymptotically nonexpansive self-mapping of $C$ has a fixed point.

There are numerous papers dealing with the approximation of fixed points of nonexpansive and asymptotically nonexpansive mappings in uniformly convex Banach spaces through modified Mann and Ishikawa iteration processes (see, e.g., [2-9] and references therein). The class of Lipschitz mappings is larger than the classes of nonexpansive and asymptotically nonexpansive mappings. However, the theory of the computation of fixed points of non-Lipschitz mappings is equally important and interesting. There are few a results in this direction (see, e.g., [10-13]).

In 1976, Lim [14] introduced a concept of convergence in a general metric space setting which he called ' $\Delta$-convergence'. In 2008, Kirk and Panyanak [15] specialized Lim's concept to $\mathrm{CAT}(0)$ spaces and showed that many Banach space results involving weak convergence have precise analogs in this setting. Since then, the existence problem and the $\Delta$-convergence problem of iterative sequences to a fixed point for nonexpansive mapping, asymptotically nonexpansive mapping, nearly asymptotically nonexpansive, asymptotically nonexpansive mapping in intermediate sense, asymptotically nonexpansive nonselfmapping via Picard, Mann [16], Ishikawa [17], Agarwal et al. [18] in the framework of 
CAT(0) space have been rapidly developed and many papers have appeared in this direction (see, e.g., [19-23]).

The purpose of the paper is to establish $\Delta$-convergence as well as strong convergence through the $S$-iteration process for a class of mappings which is essentially wider than that of asymptotically nonexpansive mappings on a nonlinear domain, uniformly convex hyperbolic space which includes both uniformly convex Banach spaces and CAT $(0)$ spaces. Therefore, our results extend and improve the corresponding ones proved by Abbas et al. [19], Dhompongsa and Panyanak [22], Khan and Abbas [23] and many other results in this direction.

\section{Preliminaries}

Let $F(T)=\{T x=x: x \in C\}$ denotes the set of fixed point. We begin with the following definitions.

Definition 2.1 Let $C$ be a nonempty subset of metric space $X$ and $T: C \rightarrow C$ a mapping. A sequence $\left\{x_{n}\right\}$ in $C$ is said to be an approximating fixed point sequence of $T$ if

$$
\lim _{n \rightarrow \infty} d\left(x_{n}, T x_{n}\right)=0 .
$$

Definition 2.2 Let $C$ be a nonempty subset of a metric space $X$. The mapping $T: C \rightarrow C$ is said to be

(1) uniformly L-Lipschitzian if for each $n \in \mathbb{N}$, there exists a positive number $L>0$ such that

$$
d\left(T^{n} x, T^{n} y\right) \leq L d(x, y) \quad \text { for all } x, y \in C
$$

(2) asymptotically nonexpansive if there exists a sequence $\left\{k_{n}\right\}$ in $[0, \infty)$ with $\lim _{n \rightarrow \infty} k_{n}=0$ such that

$$
d\left(T^{n} x, T^{n} y\right) \leq\left(1+k_{n}\right) d(x, y) \quad \text { for all } x, y \in C \text { and } n \in \mathbb{N} \text {; }
$$

(3) asymptotically quasi-nonexpansive if $F(T) \neq \emptyset$ and there exists a sequence $\left\{k_{n}\right\}$ in $[0, \infty)$ with $\lim _{n \rightarrow \infty} k_{n}=0$ such that

$$
d\left(T^{n} x_{n}, p\right) \leq\left(1+k_{n}\right) d\left(x_{n}, p\right) \quad \text { for all } x \in C, p \in F(T) \text { and } n \in \mathbb{N} .
$$

The class of nearly Lipschitzian mappings is an important generalization of the class of Lipschitzian mappings and was introduced by Sahu [11].

Let $C$ be a nonempty subset of a metric space $X$ and fix a sequence $\left\{a_{n}\right\}$ in $[0, \infty)$ with $a_{n} \rightarrow 0$. A mapping $T: C \rightarrow C$ is said to be nearly Lipschitzian with respect to $\left\{a_{n}\right\}$ if for each $n \in \mathbb{N}$, there exists a constant $k_{n} \geq 0$ such that

$$
d\left(T^{n} x, T^{n} y\right) \leq k_{n}\left(d(x, y)+a_{n}\right) \quad \text { for all } x, y \in C .
$$

The infimum of the constants $k_{n}$ for which (2.1) holds is denoted by $\eta\left(T^{n}\right)$ and is called the nearly Lipschitz constant of $T^{n}$.

A nearly Lipschitzian mapping $T$ with the sequence $\left\{\left(a_{n}, \eta\left(T^{n}\right)\right)\right\}$ is said to be 
(4) nearly nonexpansive if $\eta\left(T^{n}\right)=1$ for all $n \in \mathbb{N}$;

(5) nearly asymptotically nonexpansive if $\eta\left(T^{n}\right) \geq 1$ for all $n \in \mathbb{N}$ and $\lim _{n \rightarrow \infty} \eta\left(T^{n}\right)=1$;

(6) nearly uniformly $k$-Lipschitzian if $\eta\left(T^{n}\right) \leq k$ for all $n \in \mathbb{N}$.

Definition 2.3 Let $C$ be a nonempty subset of a metric space $X$ and fix a sequence $\left\{a_{n}\right\}$ in $[0, \infty)$ with $a_{n} \rightarrow 0$. A mapping $T: C \rightarrow C$ is said to be nearly asymptotically quasinonexpansive with respect to $\left\{a_{n}\right\}$ if $F(T) \neq \emptyset$ and there exists a sequence $\left\{u_{n}\right\}$ in $[0, \infty)$ with $\lim _{n \rightarrow \infty} u_{n}=0$ such that

$$
d\left(T^{n} x, p\right) \leq\left(1+u_{n}\right) d(x, p)+a_{n}
$$

for all $x \in C, p \in F(T)$ and $n \in \mathbb{N}$.

In fact, if $T$ is a nearly asymptotically nonexpansive mapping and $F(T)$ is nonempty, then $T$ is a nearly asymptotically quasi-nonexpansive mapping. The following is an example of a nearly asymptotically quasi-nonexpansive mapping with $F(T) \neq \phi$.

Example 2.4 [19] Let $X=\mathbb{R}, C=(-\infty, 3]$ and $T: C \rightarrow C$ be a mapping defined by

$$
T x= \begin{cases}\frac{1}{2} x & \text { if } x \in(-\infty, 2], \\ x-1 & \text { if } x \in(2,3] .\end{cases}
$$

Here, $F(T)=\{0\}$ and also, $T$ is nearly asymptotically quasi-nonexpansive mapping with $\left\{u_{n}\right\}=\left\{1, \frac{1}{2}, \frac{1}{2^{2}}, \frac{1}{2^{3}}, \ldots\right\}$ and $\left\{a_{n}\right\}=\left\{1, \frac{1}{2}, \frac{1}{2^{2}}, \frac{1}{2^{3}}, \ldots\right\}$.

A nearly asymptotically quasi-nonexpansive mapping is called a nearly quasi-nonexpansive (asymptotically quasi-nonexpansive mapping) if $u_{n}=0$ for all $n \in \mathbb{N}\left(a_{n}=0\right.$ for all $n \in \mathbb{N}$ ). Notice that every nearly asymptotically quasi-nonexpansive mapping with bounded domain is nearly quasi-nonexpansive. Indeed, if $C$ is a bounded subset of a metric space and $T: C \rightarrow C$ a nearly asymptotically quasi-nonexpansive mapping with sequence $\left\{\left(a_{n}, u_{n}\right)\right\}$, then

$$
d\left(T^{n} x, p\right) \leq\left(1+u_{n}\right) d(x, p)+a_{n} \leq d(x, p)+\left(u_{n} \sup _{x, y \in C} d(x, y)+a_{n}\right)
$$

for all $x \in C, p \in F(T)$ and $n \in \mathbb{N}$.

The following example shows that $T$ is a nearly quasi-nonexpansive mapping but not Lipschitzian and quasi-nonexpansive.

Example 2.5 [19] Let $X=\mathbb{R}, C=\left[\frac{-1}{\pi}, \frac{1}{\pi}\right]$ and $k \in(0,1)$. Let $T: C \rightarrow C$ be a mapping defined by

$$
T x= \begin{cases}0 & \text { if } x=0, \\ k x \sin \frac{1}{x} & \text { if } x \neq 0 .\end{cases}
$$

Since $T: C \rightarrow C$ is obviously continuous, it easily follows that it is uniformly continuous. Note $F(T)=\{0\}$ and $T^{n} x \rightarrow 0$ uniformly, but $T$ is not Lipschitzian. For each fixed $n \in \mathbb{N}$, 
define

$$
f_{n}(x)=\left|T^{n} x\right|-|x| \quad \text { for all } x \in C .
$$

Fix a sequence $\left\{a_{n}\right\}$ in $\mathbb{R}$ defined by

$$
a_{n}=\max \left\{\sup _{x \in C} f_{n}(x), 0\right\} \quad \text { for all } n \in \mathbb{N} \text {. }
$$

It is clear that $a_{n} \geq 0$ for all $n \in \mathbb{N}$ and $a_{n} \rightarrow 0$, since $T^{n} x \rightarrow 0$ uniformly. By the definition of $\left\{a_{n}\right\}$, we have

$$
\left|T^{n} x\right| \leq|x|+a_{n} \quad \text { for all } x \in C \text { and } n \in \mathbb{N} \text {. }
$$

Clearly, $T$ is a nearly quasi-nonexpansive mapping with respect to $\left\{a_{n}\right\}$ and it is not Lipschitz and not quasi-nonexpansive.

Lemma 2.6 [19, Lemma 2.11] Let $C$ be a nonempty subset of a metric space $(X, d)$ and $T: C \rightarrow C$ a quasi-L-Lipschitzian, i.e., $F(T) \neq \emptyset$ and there exists a constant $L>0$ such that

$$
d(T x, T y) \leq L d(x, y) \quad \text { for all } x \in C \text { and } y \in F(T) .
$$

If $\left\{x_{n}\right\}$ is a sequence in $C$ such that $\lim _{n \rightarrow \infty} d\left(x_{n}, F(T)\right)=0$ and $\lim _{n \rightarrow \infty} x_{n}=x \in C$, where $d(x, F(T))=\inf \{d(x, p): p \in F(T)\}$, then $x$ is a fixed point of $T$.

Throughout this paper we consider the following definition of a hyperbolic space introduced by Kohlenbach [24]. It is worth noting that they are different from the Gromov hyperbolic space [25] or from other notions of hyperbolic space that can be found in the literature (see, e.g., [26-28]).

Definition 2.7 A metric space $(X, d)$ is a hyperbolic space if there exists a map $W: X^{2} \times$ $[0,1] \rightarrow X$ satisfying

(i) $d(u, W(x, y, \alpha)) \leq \alpha d(u, x)+(1-\alpha) d(u, y)$,

(ii) $d(W(x, y, \alpha), W(x, y, \beta))=|\alpha-\beta| d(x, y)$,

(iii) $W(x, y, \alpha)=W(y, x,(1-\alpha))$,

(iv) $d(W(x, z, \alpha), W(y, w, \alpha)) \leq \alpha d(x, y)+(1-\alpha) d(z, w)$

for all $x, y, z, w \in X$ and $\alpha, \beta \in[0,1]$.

An important example of a hyperbolic space is a $\mathrm{CAT}(0)$ space. It is nonlinear in nature and its brief introduction is as follows.

A metric space $(X, d)$ is a length space if any two points of $X$ are joined by a rectifiable path (that is, a path of finite length) and the distance between any two points of $X$ is taken to be the infimum of the lengths of all rectifiable paths joining them. In this case, $d$ is known as a length metric (otherwise an inner metric or intrinsic metric). In the case that no rectifiable path joins two points of the space, the distance between them is taken to be $\infty$.

A geodesic path joining $x \in X$ to $y \in X$ is a map $c$ from a closed interval $[0, l] \subset \mathbb{R}$ to $X$ such that $c(0)=x, c(l)=y$, and $d\left(c(t), c\left(t^{\prime}\right)\right)=\left|t-t^{\prime}\right|$ for all $t, t^{\prime} \in[0, l]$. In particular, $c$ is an 
isometry and $d(x, y)=l$. The image $\alpha$ of $c$ is called a geodesic (or metric) segment joining $x$ and $y$. The space $(X, d)$ is said to be a geodesic space if any two points of $X$ are joined by a geodesic path and $X$ is said to be uniquely geodesic if there is exactly one geodesic path denoted by $\alpha x \oplus(1-\alpha) y$ joining $x$ and $y$ for each $x, y \in X$. The set $\{\alpha x \oplus(1-\alpha) y: \alpha \in[0,1]\}$ will be denoted by $[x, y]$, called the segment joining $x$ to $y$. A subset $C$ of a geodesic space $X$ is convex if for any $x, y \in C$, we have $[x, y] \subset C$.

A geodesic triangle $\Delta\left(x_{1}, x_{2}, x_{3}\right)$ in a geodesic metric space $(X, d)$ is defined to be a collection of three points in $X$ (the vertices of $\Delta$ ) and three geodesic segments between each pair of vertices (the edges of $\Delta$ ). A comparison triangle for geodesic triangle $\Delta\left(x_{1}, x_{2}, x_{3}\right)$ in $(X, d)$ is a triangle $\bar{\Delta}\left(x_{1}, x_{2}, x_{3}\right):=\Delta\left(\bar{x}_{1}, \bar{x}_{2}, \bar{x}_{3}\right)$ in $\mathbb{R}^{2}$ such that $d_{\mathbb{R}^{2}}\left(\bar{x}_{i}, \bar{x}_{j}\right)=d\left(x_{i}, x_{j}\right)$ for $i, j \in\{1,2,3\}$ and such a triangle always exists (see [25]).

A geodesic metric space is a CAT( 0$)$ space if all geodesic triangles $\Delta$ in $X$ with a comparison triangle $\bar{\Delta} \subset \mathbb{R}^{2}$ satisfy the $\mathrm{CAT}(0)$ inequality

$$
d(x, y) \leq d_{\mathbb{R}^{2}}(\bar{x}, \bar{y})
$$

for all $x, y \in \Delta$ and for all comparison points $\bar{x}, \bar{y} \in \bar{\Delta}$. Let $X$ be a CAT(0) space. Define $W: X^{2} \times[0,1] \rightarrow X$ by $W(x, y, \alpha)=\alpha x \oplus(1-\alpha) y$. Then $W$ satisfies the four properties of a hyperbolic space. Also if $X$ is a Banach space and $W(x, y, \alpha)=\alpha x+(1-\alpha) y$, then $X$ is a hyperbolic space. Therefore, our hyperbolic space represents a unified approach for both linear and nonlinear structures simultaneously.

To elaborate that there are hyperbolic spaces which are not imbedded in any Banach space, we give the following example.

Example 2.8 Let $B$ be the open unit ball in complex Hilbert space with respect to the Poincaré metric (also called 'Poincaré distance')

$$
d_{B}(x, y)=\arg \tanh \left|\frac{x-y}{1-x \bar{y}}\right|=\arg \tanh (1-\sigma(x, y))^{\frac{1}{2}},
$$

where

$$
\sigma(x, y)=\frac{\left(1-|x|^{2}\right)\left(1-|y|^{2}\right)}{|1-x \bar{y}|^{2}} \quad \text { for all } x, y \in B .
$$

Then $B$ is a hyperbolic space which is not imbedded in any Banach space.

A metric space $(X, d)$ is called a convex metric space introduced by Takahashi [29] if it satisfies only (i). A subset $C$ of a hyperbolic space $X$ is convex if $W(x, y, \alpha) \in C$ for all $x, y \in C$ and $\alpha \in[0,1]$.

A hyperbolic space $(X, d, W)$ is uniformly convex [30] if for any $u, x, y \in X, r>0$ and $\epsilon \in(0,2]$, there exists a $\delta \in(0,1]$ such that $d\left(W\left(x, y, \frac{1}{2}\right), u\right) \leq(1-\delta) r$ whenever $d(x, u) \leq r$, $d(y, u) \leq r$ and $d(x, y) \geq \epsilon r$.

A mapping $\eta:(0, \infty) \times(0,2] \rightarrow(0,1]$ which provides such a $\delta=\eta(r, \epsilon)$ for given $r>0$ and $\epsilon \in(0,2]$, is known as modulus of uniform convexity. We call $\eta$ monotone if it decreases with $r$ (for a fixed $\epsilon$ ).

The hyperbolic space introduced by Kohlenbach [24] is slightly restrictive than the space of hyperbolic type [26] but general than hyperbolic space of [28]. Moreover, this class 
of hyperbolic spaces also contains Hadamard manifolds, Hilbert balls equipped with the hyperbolic metric [31], $\mathbb{R}$-trees and Cartesian products of Hilbert balls as special cases.

Let $C$ be a nonempty subset of hyperbolic space $X$. Let $\left\{x_{n}\right\}$ be a bounded sequence in a hyperbolic space $X$. For $x \in X$, define a continuous functional $r_{a}\left(\cdot,\left\{x_{n}\right\}\right): X \rightarrow[0, \infty)$ by

$$
r_{a}\left(x,\left\{x_{n}\right\}\right)=\limsup _{n \rightarrow \infty} d\left(x_{n}, x\right) .
$$

The asymptotic radius $r\left(\left\{x_{n}\right\}\right)$ of $\left\{x_{n}\right\}$ is given by

$$
r\left(\left\{x_{n}\right\}\right)=\inf \left\{r_{a}\left(x,\left\{x_{n}\right\}\right): x \in X\right\} .
$$

The asymptotic center $A_{C}\left(\left\{x_{n}\right\}\right)$ of a bounded sequence of $\left\{x_{n}\right\}$ with respect to a subset of $C$ of $X$ is the set

$$
A_{C}\left(\left\{x_{n}\right\}\right)=\left\{x \in X: r_{a}\left(x,\left\{x_{n}\right\}\right) \leq r_{a}\left(y,\left\{x_{n}\right\}\right) \text { for any } y \in C\right\} .
$$

This is the set of minimizers of the functional $r_{a}\left(\cdot,\left\{x_{n}\right\}\right)$. If the asymptotic center is taken with respect to $X$, then it is simply denoted by $A\left(\left\{x_{n}\right\}\right)$.

It is well known that uniformly convex Banach spaces and even CAT(0) spaces enjoy the property that bounded sequences have unique asymptotic centers with respect to closed convex subsets. The following lemma is due to Leustean [32] and ensures that this property also holds in a complete uniformly convex hyperbolic space.

Lemma 2.9 [32] Let $(X, d, W)$ be a complete uniformly convex hyperbolic space with monotone modulus of uniform convexity. Then every bounded sequence $\left\{x_{n}\right\}$ in $X$ has a unique asymptotic center with respect to any nonempty closed convex subset $C$ of $X$.

Recall that a sequence $\left\{x_{n}\right\}$ in $X$ is said to $\Delta$-converge to $x \in X$, if $x$ is the unique asymptotic center of $\left\{u_{n}\right\}$ for every subsequence $\left\{u_{n}\right\}$ of $\left\{x_{n}\right\}$. In this case, we write $\Delta-\lim _{n} x_{n}=x$ and call $x$ the $\Delta$-limit of $\left\{x_{n}\right\}$.

Lemma 2.10 [33] Let $C$ be a nonempty closed convex subset of a uniformly convex hyperbolic space and $\left\{x_{n}\right\}$ a bounded sequence in $C$ such that $A_{C}\left(\left\{x_{n}\right\}\right)=\{y\}$ and $r\left(\left\{x_{n}\right\}\right)=\rho$. If $\left\{y_{m}\right\}$ is another sequence in $C$ such that $\lim _{m \rightarrow \infty} r_{a}\left(y_{m},\left\{x_{n}\right\}\right)=\rho$, then $\lim _{m \rightarrow \infty} y_{m}=y$.

Lemma 2.11 [33] Let $(X, d, W)$ be a uniformly convex hyperbolic space with monotone modulus of uniform convexity $\eta$. Let $x \in X$ and $\left\{t_{n}\right\}$ be a sequence in $[a, b]$ for some $a, b \in$ $(0,1)$. If $\left\{x_{n}\right\}$ and $\left\{y_{n}\right\}$ are sequences in $X$ such that

$$
\limsup _{n \rightarrow \infty} d\left(x_{n}, x\right) \leq c, \quad \limsup _{n \rightarrow \infty} d\left(y_{n}, x\right) \leq c, \quad \lim _{n \rightarrow \infty} d\left(W\left(x_{n}, y_{n}, t_{n}\right), x\right)=c
$$

for some $c \geq 0$, then $\lim _{n \rightarrow \infty} d\left(x_{n}, y_{n}\right)=0$.

Lemma 2.12 [5] Let $\left\{\delta_{n}\right\},\left\{\beta_{n}\right\}$, and $\left\{\gamma_{n}\right\}$ be three sequences of nonnegative numbers such that

$$
\delta_{n+1} \leq \beta_{n} \delta_{n}+\gamma_{n} \text { for all } n \in \mathbb{N} \text {. }
$$

If $\beta_{n} \geq 1$ for all $n \in \mathbb{N}, \sum_{n=1}^{\infty}\left(\beta_{n}-1\right)<\infty$ and $\gamma_{n}<\infty$, then $\lim _{n \rightarrow \infty} \delta_{n}$ exists. 


\section{Strong and $\boldsymbol{\Delta}$-convergence theorems in hyperbolic space}

In this section, we approximate fixed point for nearly asymptotically nonexpansive mappings in a hyperbolic space. More briefly, we established $\Delta$-convergence and strong convergence theorems for iteration scheme (3.1).

First, we define the $S$-iteration process in hyperbolic space as follows.

Let $C$ be a nonempty closed convex subset of a hyperbolic space $X$ and $T: C \rightarrow C$ be a nearly asymptotically nonexpansive mapping. Then, for arbitrarily chosen $x_{1} \in C$, we construct the sequence $\left\{x_{n}\right\}$ in $C$ such that

$$
\left\{\begin{array}{l}
x_{n+1}=W\left(T^{n} x_{n}, T^{n} y_{n}, \alpha_{n}\right), \\
y_{n}=W\left(x_{n}, T^{n} x_{n}, \beta_{n}\right), \quad n \in \mathbb{N},
\end{array}\right.
$$

where $\left\{\alpha_{n}\right\}$ and $\left\{\beta_{n}\right\}$ are sequences in $(0,1)$ is called an $S$-iteration process.

Lemma 3.1 Let $C$ be a nonempty convex subset of a hyperbolic space $X$ and $T: C \rightarrow C$ a nearly asymptotically quasi-nonexpansive mapping with sequence $\left\{\left(a_{n}, u_{n}\right)\right\}$ such that $\sum_{n=1}^{\infty} a_{n}<\infty$ and $\sum_{n=1}^{\infty} u_{n}<\infty$. Let $\left\{x_{n}\right\}$ be a sequence in $C$ defined by (3.1), where $\left\{\alpha_{n}\right\}$ and $\left\{\beta_{n}\right\}$ are sequences in $(0,1)$. Then $\lim _{n \rightarrow \infty} d\left(x_{n}, p\right)$ exists for each $p \in F(T)$.

Proof First, we show that $\lim _{n \rightarrow \infty} d\left(x_{n}, p\right)$ exists for each $p \in F(T)$, we have

$$
\begin{aligned}
d\left(x_{n+1}, p\right)= & d\left(W\left(T^{n} x_{n}, T^{n} y_{n}, \alpha_{n}\right), p\right) \\
\leq & \left(1-\alpha_{n}\right) d\left(T^{n} x_{n}, p\right)+\alpha_{n} d\left(T^{n} y_{n}, p\right) \\
\leq & \left(1-\alpha_{n}\right)\left(\left(1+u_{n}\right) d\left(x_{n}, p\right)+a_{n}\right) \\
& +\alpha_{n}\left(\left(1+u_{n}\right) d\left(y_{n}, p\right)+a_{n}\right) \\
\leq & \left(1+u_{n}\right)\left[\left(1-\alpha_{n}\right) d\left(x_{n}, p\right)+\alpha_{n} d\left(y_{n}, p\right)\right]+a_{n}
\end{aligned}
$$

and

$$
\begin{aligned}
d\left(y_{n}, p\right) & =d\left(W\left(x_{n}, T^{n} x_{n}, \beta_{n}\right), p\right) \\
& \leq\left(1-\beta_{n}\right) d\left(x_{n}, p\right)+\beta_{n} d\left(T^{n} x_{n}, p\right) \\
& \leq\left(1-\beta_{n}\right) d\left(x_{n}, p\right)+\beta_{n}\left[\left(1+u_{n}\right) d\left(x_{n}, p\right)+a_{n}\right] \\
& \leq\left(1+\beta_{n} u_{n}\right) d\left(x_{n}, p\right)+a_{n} \beta_{n},
\end{aligned}
$$

from (3.2) and (3.3), we have

$$
\begin{aligned}
& d\left(x_{n+1}, p\right) \\
& \leq\left(1+u_{n}\right)\left[\left(1-\alpha_{n}\right) d\left(x_{n}, p\right)+\alpha_{n}\left(\left(1+\beta_{n} u_{n}\right) d\left(x_{n}, p\right)+a_{n} \beta_{n}\right)+a_{n}\right] \\
& \leq\left(1+u_{n}\left(1+\alpha_{n} \beta_{n}+\alpha_{n} \beta_{n} u_{n}^{2}\right)\right) d\left(x_{n}, p\right) \\
& \quad+a_{n}\left(1+\left(1+u_{n}\right) \alpha_{n} \beta_{n}\right), \quad n \in \mathbb{N} .
\end{aligned}
$$

It follows that

$$
d\left(x_{n+1}, p\right) \leq\left(1+M u_{n}\right) d\left(x_{n}, p\right)+a_{n} M_{1}
$$


for some $M, M_{1} \geq 0 .\left\{u_{n}\right\}$ is bounded. By Lemma 2.12, we find that $\lim _{n \rightarrow \infty} d\left(x_{n}, p\right)$ exists.

Lemma 3.2 Let $C$ be a nonempty and closed convex subset of a uniformly convex hyperbolic space $X$ with monotone modulus of uniform convexity $\eta$ and let $T: C \rightarrow C$ be a nearly asymptotically quasi-nonexpansive mapping with sequences $\left\{\left(a_{n}, u_{n}\right)\right\}$ such that $\sum_{n=1}^{\infty} a_{n}<$ $\infty$ and $\sum_{n=1}^{\infty} u_{n}<\infty$. Let $F(T) \neq \emptyset$, then for the sequence $\left\{x_{n}\right\}$ in $C$ defined by (3.1), we have $\lim _{n \rightarrow \infty} d\left(x_{n}, T^{n} x_{n}\right)=0$.

Proof From Lemma 3.1, we find that $\lim _{n \rightarrow \infty} d\left(x_{n}, p\right)$ exists for each $p \in F(T)$. We suppose that $\lim _{n \rightarrow \infty} d\left(x_{n}, p\right)=c \geq 0$. Since

$$
d\left(T^{n} x_{n}, p\right) \leq\left(1+u_{n}\right) d\left(x_{n}, p\right)+a_{n} \quad \text { for all } n \in \mathbb{N},
$$

we have

$$
\limsup _{n \rightarrow \infty} d\left(T^{n} x_{n}, p\right) \leq c
$$

Also

$$
\begin{aligned}
d\left(y_{n}, p\right) & \leq d\left(W\left(x_{n}, T^{n} x_{n}, \beta_{n}\right), p\right) \\
& \leq\left(1-\beta_{n}\right) d\left(x_{n}, p\right)+\beta_{n} d\left(T^{n} x_{n}, p\right) \\
& \leq\left(1+\beta_{n} u_{n}\right) d\left(x_{n}, p\right)+a_{n} \beta_{n},
\end{aligned}
$$

which yields

$$
\limsup _{n \rightarrow \infty} d\left(y_{n}, p\right) \leq c
$$

Hence

$$
\limsup _{n \rightarrow \infty} d\left(T^{n} y_{n}, p\right) \leq \limsup _{n \rightarrow \infty}\left(\left(1+u_{n}\right) d\left(y_{n}, p\right)+a_{n}\right) \leq c
$$

Since

$$
c=\lim _{n \rightarrow \infty} d\left(x_{n+1}, p\right)=\lim _{n \rightarrow \infty} d\left(W\left(T^{n} x_{n}, T^{n} y_{n}, \alpha_{n}\right), p\right),
$$

it follow from Lemma 2.11 that

$$
\lim _{n \rightarrow \infty} d\left(T^{n} x_{n}, T^{n} y_{n}\right)=0 .
$$

From (3.1) and (3.7), we have

$$
\begin{aligned}
d\left(x_{n+1}, T^{n} x_{n}\right) & =d\left(W\left(T^{n} x_{n}, T^{n} y_{n}, \alpha_{n}\right), T^{n} x_{n}\right) \\
& \leq \alpha_{n} d\left(T^{n} x_{n}, T^{n} y_{n}\right) \\
& \leq b d\left(T^{n} x_{n}, T^{n} y_{n}\right) \rightarrow 0 \quad \text { as } n \rightarrow \infty
\end{aligned}
$$


Hence, from (3.7) and (3.8), we have

$$
d\left(x_{n+1}, T^{n} y_{n}\right) \leq d\left(x_{n+1}, T^{n} x_{n}\right)+d\left(T^{n} x_{n}, T^{n} y_{n}\right) \rightarrow 0 \quad \text { as } n \rightarrow \infty .
$$

Now using (3.9), we have

$$
\begin{aligned}
d\left(x_{n+1}, p\right) & \leq d\left(x_{n+1}, T^{n} y_{n}\right)+d\left(T^{n} y_{n}, p\right) \\
& \leq d\left(x_{n+1}, T^{n} y_{n}\right)+\left(\left(1+u_{n}\right) d\left(y_{n}, p\right)+a_{n}\right),
\end{aligned}
$$

which gives from (3.10)

$$
c \leq \liminf _{n \rightarrow \infty} d\left(y_{n}, p\right)
$$

From (3.5) and (3.11), we obtain

$$
c=\lim _{n \rightarrow \infty} d\left(y_{n}, p\right)=d\left(W\left(x_{n}, T^{n} x_{n}, \beta_{n}\right), p\right) .
$$

Apply Lemma 2.11 in (3.12), and we obtain

$$
\lim _{n \rightarrow \infty} d\left(x_{n}, T^{n} x_{n}\right)=0
$$

Theorem 3.3 Let $C$ be a nonempty closed convex subset of a complete uniformly convex hyperbolic space $X$ with monotone modulus of uniform convexity $\eta$ and let $T: C \rightarrow C$ be a uniformly continuous nearly asymptotically nonexpansive mapping with $F(T) \neq \emptyset$ and sequence $\left\{\left(a_{n}, \eta\left(T^{n}\right)\right)\right\}$ such that $\sum_{n=1}^{\infty}\left(\eta\left(T^{n}\right)-1\right)<\infty$ and $\sum_{n=1}^{\infty} a_{n}<\infty$. For arbitrary $x_{1} \in$ $C$, let $\left\{x_{n}\right\}$ be a sequence in $C$ defined by $(3.1)$, where $\left\{\alpha_{n}\right\}$ and $\left\{\beta_{n}\right\}$ are sequences in $(0,1)$. Then $\left\{x_{n}\right\}$ is $\Delta$-convergent to an element of $F(T)$.

Proof By Lemma 3.2, $\lim _{n \rightarrow \infty} d\left(x_{n}, T^{n} x_{n}\right)=0$. By uniform continuity of $T, d\left(x_{n}, T^{n} x_{n}\right) \rightarrow 0$ implies that $d\left(T x_{n}, T^{n+1} x_{n}\right) \rightarrow 0$, observe that

$$
\begin{aligned}
d\left(x_{n+1}, x_{n}\right) & \leq d\left(W\left(T^{n} x_{n}, T^{n} y_{n}, \alpha_{n}\right), x_{n}\right) \\
& \leq\left(1-\alpha_{n}\right) d\left(x_{n}, T^{n} x_{n}\right)+\alpha_{n} d\left(T^{n} y_{n}, x_{n}\right) \\
& \leq d\left(x_{n}, T^{n} x_{n}\right)+\alpha_{n} d\left(T^{n} y_{n}, T^{n} x_{n}\right) \\
& \leq d\left(x_{n}, T^{n} x_{n}\right)+\eta\left(T^{n}\right)\left(d\left(x_{n}, y_{n}\right)+a_{n}\right) \\
& \leq d\left(x_{n}, T^{n} x_{n}\right)+\eta\left(T^{n}\right)\left(d\left(x_{n}, T^{n} x_{n}\right)+a_{n}\right) \\
& \rightarrow 0 \quad \text { as } n \rightarrow \infty .
\end{aligned}
$$

Also

$$
\begin{aligned}
d\left(x_{n}, T x_{n}\right) \leq & d\left(x_{n}, x_{n+1}\right)+d\left(x_{n+1}, T^{n+1} x_{n+1}\right) \\
& +d\left(T^{n+1} x_{n+1}, T^{n+1} x_{n}\right)+d\left(T^{n+1} x_{n}, T x_{n}\right) \\
\leq & \left(1+\eta\left(T^{n}\right) d\left(x_{n}, x_{n+1}\right)\right)+d\left(x_{n+1}, T^{n} x_{n+1}\right) \\
& +d\left(T^{n+1} x_{n}, T x_{n}\right)+a_{n+1},
\end{aligned}
$$


and hence

$$
\lim _{n \rightarrow \infty} d\left(x_{n}, T x_{n}\right)=0 .
$$

Next, we have to show that $\left\{x_{n}\right\}$ is $\Delta$-convergent to an element of $F(T)$.

Since $\left\{x_{n}\right\}$ is bounded (by Lemma 3.1) therefore, Lemma 2.9 asserts that $\left\{x_{n}\right\}$ has a unique asymptotic center. That is, $A\left(\left\{x_{n}\right\}\right)=\{x\}$ (say). Let $A\left(\left\{y_{n}\right\}\right)=\{v\}$. Then by (3.13), $\lim _{n \rightarrow \infty} d\left(y_{n}, T y_{n}\right)=0 . T$ is a nearly asymptotically nonexpansive mapping with sequence $\left\{\left(a_{n}, \eta\left(T^{n}\right)\right)\right\}$. By uniform continuity of $T$

$$
\lim _{n \rightarrow \infty} d\left(T^{i} y_{n}, T^{i+1} y_{n}\right)=0 \quad \text { for } i=1,2,3, \ldots
$$

Now we claim that $v$ is a fixed point of $T$. For this, we define a sequence $\left\{z_{n}\right\}$ in $C$ by $z_{m}=T^{m} v, m \in \mathbb{N}$. For integers $m, n \in \mathbb{N}$, we have

$$
\begin{aligned}
d\left(z_{m}, y_{n}\right) & \leq d\left(T^{m} v, T^{m} y_{n}\right)+d\left(T^{m} y_{n}, T^{m-1} y_{n}\right)+\cdots+d\left(T y_{n}, y_{n}\right) \\
& \leq \eta\left(T^{m}\right)\left(d\left(v, y_{n}\right)+a_{m}\right)+\sum_{i=0}^{m-1} d\left(T^{i} y_{n}, T^{i+1} y_{n}\right) .
\end{aligned}
$$

Then, by (3.14) and (3.15), we have

$$
\begin{aligned}
r_{a}\left(z_{m},\left\{y_{n}\right\}\right) & =\limsup _{m \rightarrow \infty} d\left(z_{m}, y_{n}\right) \\
& \leq \eta\left(T^{m}\right)\left[r_{a}\left(v,\left\{y_{n}\right\}\right)+a_{m}\right] .
\end{aligned}
$$

Hence

$$
\limsup _{m \rightarrow \infty} r_{a}\left(z_{m},\left\{y_{n}\right\}\right) \leq r_{a}\left(v,\left\{y_{n}\right\}\right)
$$

Since $A_{C}\left(\left\{y_{n}\right\}\right)=\{v\}$, by definition of asymptotic center $A_{C}\left(\left\{y_{n}\right\}\right)$ of a bounded sequence $\left\{y_{n}\right\}$ with respect to $C \subset X$, we have

$$
r_{a}\left(v,\left\{y_{n}\right\}\right) \leq r_{a}\left(y,\left\{y_{n}\right\}\right), \quad \forall y \in C .
$$

This implies that

$$
\liminf _{m \rightarrow \infty} r_{a}\left(z_{m},\left\{y_{n}\right\}\right) \geq r_{a}\left(v,\left\{y_{n}\right\}\right),
$$

therefore, from (3.16) and (3.17), we have

$$
\lim _{m \rightarrow \infty} r_{a}\left(z_{m},\left\{y_{n}\right\}\right)=r_{a}\left(v,\left\{y_{n}\right\}\right) .
$$

It follows from Lemma 2.10 that $T^{m} v \rightarrow v$. By uniform continuity of $T$, we have

$$
T v=T\left(\lim _{m \rightarrow \infty} T^{m} v\right)=T^{m+1} v=v,
$$

which implies that $v$ is a fixed point of $T$, i.e., $v \in F(T)$. 
Next, we claim that $v$ is the unique asymptotic center for each subsequence $\left\{y_{n}\right\}$ of $\left\{x_{n}\right\}$. Assume contrarily, that is, $x \neq v$. Since $\lim _{n \rightarrow \infty} d\left(x_{n}, v\right)$ exists by Lemma 3.1, therefore, by the uniqueness of asymptotic centers, we have

$$
\begin{array}{r}
\limsup _{n \rightarrow \infty} d\left(y_{n}, v\right)<\limsup _{n \rightarrow \infty} d\left(y_{n}, x\right) \\
\leq \limsup _{n \rightarrow \infty} d\left(x_{n}, x\right) \\
<\limsup _{n \rightarrow \infty} d\left(x_{n}, v\right) \\
=\limsup d\left(y_{n}, v\right),
\end{array}
$$

a contradiction and hence $x=v$. Since $\left\{y_{n}\right\}$ is an arbitrary subsequence of $\left\{x_{n}\right\}$, therefore, $A_{C}\left(\left\{y_{n}\right\}\right)=\{v\}$ for all subsequence of $\left\{y_{n}\right\}$ of $\left\{x_{n}\right\}$. This proves that $\left\{x_{n}\right\} \Delta$-converges to a fixed point of $T$.

We now discuss the strong convergence for the $S$-iteration process defined by (3.1) for Lipschitzian type mappings in a uniformly convex hyperbolic space setting.

Theorem 3.4 Let $C$ be a nonempty closed convex subset of a complete uniformly convex hyperbolic space $X$ with monotone modulus of uniform convexity $\eta$ and let $T: C \rightarrow C$ be a nearly asymptotically quasi-nonexpansive mapping with sequence $\left\{\left(a_{n}, u_{n}\right)\right\}$ such that $\sum_{n=1}^{\infty} a_{n}<\infty$ and $\sum_{n=1}^{\infty} u_{n}<\infty$. Assume that $F(T)$ is a closed set. Let $\left\{x_{n}\right\}$ be a sequence in $C$ defined by (3.1), where $\left\{\alpha_{n}\right\}$ and $\left\{\beta_{n}\right\}$ are sequences in $(0,1)$. Then $\left\{x_{n}\right\}$ converges strongly to a fixed point of $T$ if and only if $\liminf _{n \rightarrow \infty} d\left(x_{n}, F(T)\right)=0$.

Proof Necessity is obvious.

Conversely, suppose that $\liminf _{n \rightarrow \infty} d\left(x_{n}, F(T)\right)=0$. From (3.4), we have

$$
d\left(x_{n+1}, F(T)\right) \leq\left(1+M u_{n}\right) d\left(x_{n}, F(T)\right)+M_{1} a_{n}, \quad n \in \mathbb{N},
$$

so $\lim _{n \rightarrow \infty} d\left(x_{n}, F(T)\right)$ exists. It follows that $\lim _{n \rightarrow \infty} d\left(x_{n}, F(T)\right)=0$. Next, we show that $\left\{x_{n}\right\}$ is a Cauchy sequence. The following arguments are similar to those given in [34, Lemma 5] and [19, Theorem 4.3], and we obtain the following inequality:

$$
d\left(x_{n+m}, p\right) \leq L\left[d\left(x_{n}, p\right)+\sum_{j=n}^{\infty} b_{j}\right]
$$

for every $p \in F(T)$ and for all $m, n \geq 1$, where $L=e^{M\left(\sum_{j=n}^{n+m-1} u_{j}\right)}>0$ and $b_{j}=M_{1} a_{j}$. As, $\sum_{n=1}^{\infty} u_{n}<\infty$ so $L^{*}=e^{M\left(\sum_{n=1}^{\infty} u_{n}\right)} \geq L=e^{M\left(\sum_{j=n}^{n+m-1} u_{j}\right)}>0$. Let $\epsilon>0$ be arbitrarily chosen. Since $\lim _{n \rightarrow \infty} d\left(x_{n}, F\right)=0$ and $\sum_{n=1}^{\infty} a_{n}<\infty$, there exists a positive integer $n_{0}$ such that

$$
d\left(x_{n}, F\right)<\frac{\epsilon}{4 L^{*}} \quad \text { and } \quad \sum_{j=n_{0}}^{\infty} b_{j}<\frac{\epsilon}{6 L^{*}}, \quad \forall n \geq n_{0} .
$$

In particular, $\inf \left\{d\left(x_{n_{0}}, p\right): p \in F\right\}<\frac{\epsilon}{4 L^{*}}$. Thus there must exist $p^{*} \in F$ such that

$$
d\left(x_{n_{0}}, p^{*}\right)<\frac{\epsilon}{3 L^{*}} .
$$


Hence for $n \geq n_{0}$, we have

$$
\begin{aligned}
d\left(x_{n+m}, x_{n}\right) & \leq d\left(x_{n+m}, p^{*}\right)+d\left(p^{*}, x_{n}\right) \\
& \leq 2 L^{*}\left[d\left(x_{n_{0}}, p^{*}\right)+\sum_{j=n_{0}}^{\infty} b_{j}\right] \\
& <2 L^{*}\left(\frac{\epsilon}{3 L^{*}}+\frac{\epsilon}{6 L^{*}}\right)=\epsilon .
\end{aligned}
$$

Hence $\left\{x_{n}\right\}$ is a Cauchy sequence in closed subset $C$ of a complete hyperbolic space and so it must converge strongly to a point $q$ in $C$. Now, $\lim _{n \rightarrow \infty} d\left(x_{n}, F(T)\right)=0$ gives $d(q, F(T))=0$. Since $F(T)$ is closed, we have $q \in F(T)$.

In the next result, the closedness assumption on $F(T)$ is not required.

Theorem 3.5 Let $C$ be a nonempty closed convex subset of a complete uniformly convex hyperbolic space $X$ with monotone modulus of uniform convexity $\eta$ and $T: C \rightarrow C$ an asymptotically quasi-nonexpansive mapping with sequence $\left\{u_{n}\right\}$ such that $\sum_{n=1}^{\infty} u_{n}<\infty$. Let $\left\{x_{n}\right\}$ be a sequence in $C$ defined by (3.1), where $\left\{\alpha_{n}\right\}$ and $\left\{\beta_{n}\right\}$ are sequences in $(0,1)$. Then $\left\{x_{n}\right\}$ converges strongly to a fixed point of $T$ if $\liminf _{n \rightarrow \infty} d\left(x_{n}, F(T)\right)=0$.

Proof Following an argument similar to those of Theorem 3.4, we see that $\left\{x_{n}\right\}$ is a Cauchy sequence in $C$. Let $\lim _{n \rightarrow \infty} x_{n}=x$. Since an asymptotically quasi-nonexpansive mapping is quasi-L-Lipschitzian, it follows from Lemma 2.6 that $x$ is a fixed point of $T$.

Theorem 3.6 Let $C$ be a nonempty closed convex subset of a complete uniformly convex hyperbolic space $X$ with monotone modulus of uniform convexity $\eta$ and $T: C \rightarrow C$ a uniformly continuous nearly asymptotically nonexpansive mapping with $F(T) \neq \emptyset$ and sequence $\left\{a_{n}, \eta\left(T^{n}\right)\right\}$ such that $\sum_{n=1}^{\infty}\left(\eta\left(T^{n}\right)-1\right)<\infty$ and $a_{n}<\infty$. For arbitrary $x_{1} \in C$, let $\left\{x_{n}\right\}$ be a sequence in $C$ defined by (3.1), where $\left\{\alpha_{n}\right\}$ and $\left\{\beta_{n}\right\}$ are sequences in $(0,1)$. If $T$ is uniformly continuous and $T^{m}$ is demicompact for some $m \in N$, it follows that $\left\{x_{n}\right\}$ converges strongly to a fixed point of $T$.

Proof By (3.13), we have $\lim _{n \rightarrow \infty} d\left(x_{n}, T x_{n}\right)=0$. By the uniformly continuous of $T$, we have

$$
d\left(x_{n}, T x_{n}\right) \rightarrow 0 \Rightarrow d\left(T x, T^{2} x_{n}\right) \rightarrow 0 \quad \Rightarrow \quad \cdots \quad \Rightarrow \quad d\left(T^{i} x_{n}, T^{i+1} x_{n}\right) \rightarrow 0
$$

for all $i \in \mathbb{N}$. It follows that

$$
d\left(x_{n}, T^{m} x_{n}\right) \leq \sum_{i=0}^{m-1} d\left(T^{i} x_{n}, T^{i+1} x_{n}\right) \rightarrow 0 \quad \text { as } n \rightarrow \infty
$$

Since $d\left(x_{n}, T^{m} x_{n}\right) \rightarrow 0$, and $T^{m}$ is demicompact, there exists a subsequence $\left\{x_{n_{j}}\right\}$ of $\left\{x_{n}\right\}$ such that $\lim _{j \rightarrow \infty} T^{m} x_{n_{j}}=x \in C$.

Note that

$$
d\left(x_{n_{j}}, x\right) \leq d\left(x_{n_{j}}, T^{m} x_{n_{j}}\right)+d\left(T^{m} x_{n_{j}}, x\right) \rightarrow 0 \quad \text { as } j \rightarrow \infty
$$


Since $\lim _{n \rightarrow \infty} d\left(x_{n}, T x_{n}\right)=0$, we get $x \in F(T)$. Since $\lim _{n \rightarrow \infty} d\left(x_{n}, x\right)$ exists by Lemma 3.1, and $\lim _{j \rightarrow \infty} d\left(x_{n_{j}}, x\right)=0$, we conclude that $x_{n} \rightarrow x$.

Recall that a mapping $T$ from a subset of a metric space $(X, d)$ into itself with $F(T) \neq \emptyset$ is said to satisfy condition (A) (see [35]) if there exists a nondecreasing function $f:[0, \infty) \rightarrow$ $[0, \infty)$ with $f(0)=0, f(t)>0$ for $t \in(0, \infty)$ such that

$$
d(x, T x) \geq f(d(x, F(T))) \text { for all } x \in C .
$$

Theorem 3.7 Let $C$ be a nonempty closed convex subset of a complete uniformly convex hyperbolic space $X$ with monotone modulus of uniform convexity $\eta$ and $T: C \rightarrow C$ a uniformly continuous nearly asymptotically nonexpansive mapping with $F(T) \neq \emptyset$ and sequence $\left\{\left(a_{n}, \eta\left(T^{n}\right)\right)\right\}$ such that $\sum_{n=1}^{\infty} \eta\left(T^{n}-1\right)<\infty$ and $\sum_{n=1}^{\infty} a_{n}<\infty$. For arbitrary $x_{1} \in C$, let $\left\{x_{n}\right\}$ be a sequence in $C$ defined by (3.1), where $\left\{\alpha_{n}\right\}$ and $\left\{\beta_{n}\right\}$ are sequences in $(0,1)$. Suppose that $T$ satisfies the condition (A). Then $\left\{x_{n}\right\}$ converges strongly to a fixed point of $T$.

Proof By (3.13), we have $\lim _{n \rightarrow \infty} d\left(x_{n}, T x_{n}\right)=0$ Further, by condition (A),

$$
\lim _{n \rightarrow \infty} d\left(x_{n}, T x_{n}\right) \geq \lim _{n \rightarrow \infty} f\left(d\left(x_{n}, F(T)\right)\right) .
$$

It follows that $\lim _{n \rightarrow \infty} d\left(x_{n}, F(T)\right)=0$. Therefore, the result follows from Theorem 3.4.

\section{Conclusion}

1. We prove strong and $\Delta$-convergence of the $S$-iteration process, which is faster than the iteration processes used by Abbas et al. [19], Dhompongsa and Panyanak [22], and Khan and Abbas [23].

2. Theorem 3.3 extends Agarwal et al. [18, Theorem 3.8] from a uniformly convex Banach space to a uniformly convex hyperbolic space.

3. Theorem 3.3 extends Dhompongsa and Panyanak [22, Theorem 3.3] from the class of nonexpansive mappings to the class of mappings which are not necessarily Lipschitzian.

4. Theorem 3.6, extends corresponding results of Beg [36], Chang [37], Khan and Takahashi [4] and Osilike and Aniagbosor [5] for a more general class of non-Lipschitzian mappings in the framework of a uniformly convex hyperbolic space. It also extends the corresponding results of Dhomponsga and Panyanak [22] from the class of nonexpansive mappings to a more general class of non-Lipschitzian mappings in the same space setting.

5. Theorem 3.7 extends Sahu and Beg [12, Theorem 4.4] from a Banach to a uniformly convex hyperbolic space.

Competing interests

The authors declare that they have no competing interests.

Authors' contributions

All authors read and approved the final manuscript.

\section{Author details}

'Department of Mathematics and RINS, Gyeongsang National University, Jinju, 660-701, Korea. ${ }^{2}$ Department of Applied Mathematics, Shri Shankaracharya Group of Institutions, Junwani, Bhilai, 490020, India. ${ }^{3}$ Department of Mathematics, Lahore Leads University, Lahore, 54810, Pakistan. 


\section{Acknowledgements}

The authors would like to thank the editor and all referees for their valuable comments and suggestions for improving the paper.

Received: 17 April 2014 Accepted: 31 October 2014 Published: 12 Nov 2014

\section{References}

1. Goebel, K, Kirk, WA: A fixed point theorem for asymptotically nonexpansive mappings. Proc. Am. Math. Soc. 35, 171-174 (1972). doi:10.1090/S0002-9939-1972-0298500-3

2. Agarwal, RP, O'Regan, D, Sahu, DR: Fixed Point Theory for Lipschitzian-Type Mappings with Applications. Topological Fixed Point Theory and Its Applications, vol. 6. Springer, New York (2009)

3. Jung, JS, Sahu, DR: Dual convergences of iteration processes for nonexpansive mappings in Banach space. Czechoslov. Math. J. 53, 397-404 (2003). doi:10.1023/A:1026291421505

4. Khan, SH, Takahashi, W: Iterative approximation of fixed points of asymptotically nonexpansive mappings with compact domains. Panam. Math. J. 11, 19-24 (2001)

5. Osilike, MO, Aniagbosor, SC: Weak and strong convergence theorems for fixed points of asymptotically nonexpansive mappings. Math. Comput. Model. 32, 1181-1191 (2000). doi:10.1016/S0895-7177(00)00199-0

6. Schu, J: Iterative construction of fixed points of asymptotically nonexpansive mappings. J. Math. Anal. Appl. 158, 407-413 (1991). doi:10.1016/0022-247X(91)90245-U

7. Tan, KK, Xu, HK: Approximating fixed points of nonexpansive mappings by the Ishikawa iteration process. J. Math. Anal. Appl. 178, 301-308 (1993). doi:10.1006/jmaa.1993.1309

8. Tan, KK, Xu, HK: Fixed point iteration processes for asymptotically nonexpansive mappings. Proc. Am. Math. Soc. 122, 733-739 (1994). doi:10.1090/S0002-9939-1994-1203993-5

9. Xu, HK: Existence and convergence for fixed points of mappings of asymptotically nonexpansive type. Nonlinear Anal. 16, 1139-1146 (1991). doi:10.1016/0362-546X(91)90201-B

10. Kim, GE, Kim, TH: Mann and Ishikawa iterations with errors for non-Lipschitzian mappings in Banach spaces. Comput. Math. Appl. 42, 1565-1570 (2001). doi:10.1016/S0898-1221(01)00262-0

11. Sahu, DR: Fixed points of demicontinuous nearly Lipschitzian mappings in Banach spaces. Comment. Math. Univ. Carol. 46, 653-666 (2005)

12. Sahu, DR, Beg, I: Weak and strong convergence for fixed points of nearly asymptotically nonexpansive mappings. Int. J. Mod. Math. 3, 135-151 (2008)

13. Shahzad, $\mathrm{N}$, Zegeye, $\mathrm{H}$ : Strong convergence of an implicit iteration process for a finite family of generalized asymptotically quasi-nonepxpansive maps. Appl. Math. Comput. 189, 1058-1065 (2007). doi:10.1016/j.amc.2006.11.152

14. Lim, TC: Remarks on some fixed point theorems. Proc. Am. Math. Soc. 60, 179-182 (1976) doi:10.1090/S0002-9939-1976-0423139-X

15. Kirk, WA, Panyanak, B: A concept of convergence in geodesic spaces. Nonlinear Anal. 68, 3689-3696 (2008) doi:10.1016/j.na.2007.04.011

16. Mann, WR: Mean value methods in iteration. Proc. Am. Math. Soc. 4, 506-510 (1953). doi:10.1090/S0002-9939-1953-0054846-3

17. Ishikawa, S: Fixed points by new iteration method. Proc. Am. Math. Soc. 44, 147-150 (1974). doi:10.1090/S0002-9939-1974-0336469-5

18. Agarwal, RP, O'Regan, D, Sahu, DR: Iterative construction of fixed points of nearly asymptotically nonexpansive mappings. J. Nonlinear Convex Anal. 8, 61-79 (2007)

19. Abbas, M, Kadelburg, Z, Sahu, DR: Fixed point theorems for Lipschitzian type mappings in CAT(0) spaces. Math. Comput. Model. 55, 1418-1427 (2012). doi:10.1016/j.mcm.2011.10.019

20. Abbas, M, Thakur, BS, Thakur, D: Fixed points of asymptotically nonexpansive mappings in the intermediate sense in CAT(0) spaces. Commun. Korean Math. Soc. 28, 107-121 (2013). doi:10.4134/CKMS.2013.28.1.107

21. Chang, SS, Wang, L, Lee, HWJ, Chen, CK, Yang, L: Demiclosedness principle and $\Delta$-convergence theorems for total asymptotically nonexpansive mappings in CAT(0) spaces. Appl. Math. Comput. 219, 2611-2617 (2012). doi:10.1016/j.amc.2012.08.095

22. Dhompongsa, S, Panyanak, B: On $\Delta$-convergence theorems in CAT(0) spaces. Comput. Math. Appl. 56, 2572-2579 (2008). doi:10.1016/j.camwa.2008.05.036

23. Khan, $\mathrm{SH}, \mathrm{Abbas}, \mathrm{M}$ : Strong and $\Delta$-convergence of some iterative schemes in CAT(0) spaces. Comput. Math. Appl. 61 109-116 (2011). doi:10.1016/j.camwa.2010.10.037

24. Kohlenbach, U: Some logical metatheorems with applications in functional analysis. Trans. Am. Math. Soc. 357 89-128 (2005). doi:10.1090/S0002-9947-04-03515-9

25. Bridson, M, Haefliger, A: Metric Space of Non-positive Curvature. Springer, Berlin (1999)

26. Goebel, K, Kirk, WA: Iteration processes for nonexpansive mappings. In: Singh, SP, Thomeier, S, Watson, B (eds.) Topological Methods in Nonlinear Functional Analysis. Contemporary Mathematics, vol. 21, pp. 115-123 (1983)

27. Kirk, WA: Krasnoselskii's iteration process in hyperbolic space. Numer. Funct. Anal. Optim. 4, $371-381$ (1982). doi:10.1080/01630568208816123

28. Reich, S, Shafrir, I: Nonexpansive iterations in hyperbolic spaces. Nonlinear Anal. 15, 537-558 (1990). doi:10.1016/0362-546X(90)90058-O

29. Takahashi, W: A convexity in metric spaces and nonexpansive mappings. Kodai Math. Semin. Rep. 22, 142-149 (1970)

30. Shimizu, T, Takahashi, W: Fixed points of multivalued mappings in certain convex metric spaces. Topol. Methods Nonlinear Anal. 8, 197-203 (1996)

31. Goebel, K, Reich, S: Uniform Convexity, Hyperbolic Geometry, and Nonexpansive Mappings. Dekker, New York (1984)

32. Leustean, L: Nonexpansive iteration in uniformly convex W-hyperbolic spaces. In: Leizarowitz, A, Mordukhovich, BS Shafrir, I, Zaslavski, A (eds.) Nonlinear Analysis and Optimization I: Nonlinear Analysis. Contemporary Mathematics, vol. 513, pp. 193-210. Am. Math. Soc., Providence (2010)

33. Khan, AR, Fukhar-ud-din, $H$, Khan, MAA: An implicit algorithm for two finite families of nonexpansive maps in hyperbolic spaces. Fixed Point Theory Appl. 2012, 54 (2012). doi:10.1186/1687-1812-2012-54 
34. Fukhar-ud-din, $\mathrm{H}$, Khan, $\mathrm{SH}$ : Convergence of iterates with errors of asymptotically nonexpansive mappings and applications. J. Math. Anal. Appl. 328, 821-829 (2007). doi:10.1016/j.jmaa.2006.05.068

35. Senter, HF, Doston, WG: Approximating fixed points of nonexpansive mappings. Proc. Am. Math. Soc. 44, 375-380 (1974). doi:10.1090/S0002-9939-1974-0346608-8

36. Beg, I: An iteration scheme for asymptotically nonexpansive mappings on uniformly convex metric spaces. Nonlinear Anal. Forum 6, 27-34 (2001)

37. Chang, SS: On the approximation problem of fixed points for asymptotically nonexpansive mappings. Indian J. Pure Appl. Math. 32, 1297-1307 (2001)

10.1186/1687-1812-2014-229

Cite this article as: Kang et al.: On the convergence of fixed points for Lipschitz type mappings in hyperbolic spaces. Fixed Point Theory and Applications 2014, 2014:229

Submit your manuscript to a SpringerOpen ${ }^{\odot}$ journal and benefit from:

- Convenient online submission

- Rigorous peer review

- Immediate publication on acceptance

- Open access: articles freely available online

- High visibility within the field

- Retaining the copyright to your article

Submit your next manuscript at $>$ springeropen.com 